DASTON, Lorraine. Historicidade e objetividade. Tradução: Derley Menezes Alves e Francine Iegelski (Org. Tiago Santos Almeida).

São Paulo: Editora LiberArs, 2017.

\title{
Os caminhos de Lorraine Daston entre a objetividade e a historicidade: orientações para uma epistemologia histórica e o desvio science studies
}

\author{
Maria Helena Silva Soares \\ helenastraub@gmail.com \\ Doutoranda PPGFIL-UERJ
}

Recebido em: 22/11/2018

Aceito em: 22/11/2018
A publicação de Historicidade e objetividade de autoria de Lorraine Daston, e organização de Tiago Santos Almeida, é uma verdadeira conquista para pesquisadores brasileiros da Filosofia, Sociologia e História da ciência. A tradução de sete textos da historiadora da ciência e diretora do Instituto Max Planck para a História da Ciência em Berlim, inaugura o acesso à pesquisa em nossa língua pátria de parte imprescindível para os estudos sobre a objetividade e a epistemologia histórica. O desconhecimento por grande parte do corpo discente, sobretudo ainda na graduação, dos escritos de Daston denota a importância desta tradução para a formação de filósofos, sociólogos e historiadores da ciência.

É preciso reconhecer que, juntamente com Peter Galison, Daston é mais conhecida pela obra Objectivity (2008). Nesta publicação, os autores abordam a objetividade como uma das virtudes epistêmicas que constituem o empreendimento científico a partir de aspectos, ao mesmo tempo, epistemológicos, sociais, éticos e psicológicos. Tais características não são usadas para diminuir a relevância da objetividade para o edifício da ciência, mas, ao contrário, para justificar a sua preponderância sobre outras categorias históricas, como a própria noção de verdade. Ao que a autora denomina falácia da história da objetividade, isto é, uma crítica à ideia de que a pesquisa histórica deslegitimaria a objetividade como um valor para a ciência.

Esta obra, Objectivity, infelizmente ainda sem tradução para o português, reflete sobre a objetividade a partir do uso de imagens feito pelas ciências como um aspecto importante para entendê-la como "modos de ver a natureza e o mundo" (FIGUEIRÔA, S., 2008, p. 107). Mapas, fotos e outros instrumentos são vestígios usados na análise sobre tipos de objetividades, como a mecânica, 
por exemplo, e ilustram de forma ainda mais notável os problemas e os objetos científicos. Reconhecemos, por isso, a importância do exercício da tradução como forma de divulgação do conhecimento e formação de pesquisadores sérios para às ciências que se debruçam sobre a história da ciência.

Daston salienta que esta empreitada, a tradução de alguns de seus escritos, é tanto uma honra quanto um desafio. Uma honra por ser reconhecida em outras tradições intelectuais. E um desafio pelo próprio ato de traduzir. Ou seja, do ato de transformar o texto original em uma versão distinta dos limites da língua em foi escrito. Na produção de um texto novo e, ainda assim, comensurável à matriz.

A este desafio soma-se também a coragem de agrupar textos escritos ou apresentados em épocas e com perspectivas distintas. A coleção selecionou trabalhos de Daston de 1992 até 2014. Isto nos permitiu acompanhar os caminhos da autora, visualizar sua "mente em movimento", em direção à epistemologia histórica. Uma boa curiosidade sobre esta organização é que, ao perscrutar a análise das categorias de objetividade e historicidade em sua trajetória acadêmica, opera, em si, o próprio desenvolvimento da epistemologia histórica que a autora defende.

O primeiro capítulo, Objetividade e a fuga da perspectiva, é um texto de 1992 publicado originalmente na Social Studies of Science e remonta à história da objetividade a fim de afirmar a pluralidade de significados e funções que ela carrega. "A história da objetividade é uma história intelectual e social, mas também é uma história moral" (DASTON, 2017, p. 36). Isto posto, Daston distingue a objetividade ontológica, a objetividade mecânica e a objetividade aperspectivística a fim de contrapor ao senso comum de que a objetividade teria sido sempre um valor epistêmico universal das ciências naturais. Essas formas de objetividades foram empregadas em momentos e em comunidades científicas distintos para afastar ora a subjetividade, ora a perspectiva ou, ainda, as idiossincrasias. A historiadora reconhece também que a objetividade teria nascido antes na estética e na filosofia moral do que nas ciências naturais. Isto é importante por desmistificar a ideia de que a objetividade nasceu pronta e relacionada à produção de saber científico desinteressado e livre de idiossincrasias. Ao contrário, o texto apresenta como a objetividade aperspectivística, enquanto valor moral, foi moldada por diferentes áreas a partir do século XIX antes de ser apropriada às ciências naturais.

O segundo e o terceiro capítulos são mais próximos, A economia moral da ciência foi publicado em 1995, na Osiris, e Uma história da objetividade em 1998, no Cahiers des Annales. No primeiro, a autora define a economia moral da ciência por contraste ao ethos mertoniano. Para Daston, economias morais se diferenciam por serem "historicamente criadas, modificadas e destruídas; impostas pela cultura ao invés da natureza e, portanto, igualmente mutáveis e violáveis; e essenciais aos modos científicos do conhecimento" (DASTON, 2017, p. 44). Para justificar isso, a historiadora recorre ao exame de três exemplos - quantificação, empirismo e objetividade - de como economias morais estruturaram aspectos chaves do conhecimento. No texto de 1998, Daston atenta para os problemas que marcam a trajetória das três escolas historiográficas que dominaram a história das ciências dos vinte e cinco anos precedentes. A escola filosófica, a escola sociológica e a escola histórica guardariam erros e acertos imprescindíveis à história das ciências e abrir mão de uma delas seria o mesmo que "amputar um membro de um corpo". Deste modo, a historiadora propõe a historical epistemology como um novo programa que poderia apropriar-se positivamente dessas escolas e superá-las. Este programa é por ela definido como:

a história das categorias que estruturam nosso pensamento, que modelam nossa concepção da argumentação e da prova, que organizam nossas práticas, que validam nossas formas de explicação e que dotam cada uma dessas atividades de um significado simbólico e de um valor afetivo. Essa epistemologia histórica pode (e, de fato, ela deve) remeter à história das ideias e das práticas tanto quanto à história das significações e dos valores que constituem as economias morais das ciências (DASTON, 2017, p. 71-72).

Em seguida, a historiadora analisa por meio da epistemologia histórica um dos seus principais temas de pesquisa, a saber, a objetividade. 
O quarto e o quinto capítulos, apesar de cronologicamente distantes, tratam das noções complementares de objeto e observação científicos. Em O que pode um objeto científico? Reflexões sobre monstros e meteoros, publicado em 1998 na Bulletin of the American Academy of Arts, Daston se interessa pelos aspectos ontológicos, epistemológicos, metodológicos, funcionais, simbólicos e/ou estéticos que qualificam ou desqualificam os objetos para as ciências. A autora se vale de exemplos históricos para contestar a tese aristotélica de que a regularidade seria uma condição suficiente ou, mesmo, necessária para a objetividade científica.

A filosofia natural tinha seu próprio critério tradicional para o maravilhoso, se não para o raro: a ignorância das causas provoca espanto que, por sua vez, é a origem da filosofia. Consequentemente, o conhecimento das causas destrói o maravilhoso, do mesmo modo que olhar por trás das cortinas de um show de marionetes diminui a maravilha das pequenas figuras aparentemente dotadas de movimento independentes (DASTON, 2017, p. 86)

Daston busca nos estudos acerca de fenômenos praeter naturam (além da natureza), de filósofos naturais dos séculos XVI e XVII, exemplos de objetos que desafiavam as explicações convencionais e suscitavam o maravilhamento, como uma verdadeira paixão cognitiva capaz de gerar objetos científicos. A autora conclui o texto com uma observação sobre a morte da filosofia preternatural em fins do século XVII, em uma espécie de desencantamento do mundo ao "abrir as cortinas de um teatro de fantoches". Tais considerações nos preparam para as observações do próximo artigo.

Sobre a observação científica, publicado originalmente dez anos depois do texto anterior, busca entender "como a observação especializada discerne e estabiliza objetos científicos para uma comunidade de pesquisadores" (DASTON, 2017, p.92). Para isso, a autora retoma as considerações de Ludwik Fleck ${ }^{1}$ que atrela o saber ver do cientista a uma experiência acumulada, não somente de um indivíduo em formação, mas sim de uma coletividade bem treinada. "Certa, rápida e silenciosa, "sem pausa para análise mental", a observação é fundada em longa familiaridade com os fenômenos em questão, sejam eles maçaricos-reais ou bactérias do tipo estreptococos" (DASTON, 2017, p.96). Essa "longa familiaridade" é um processo tanto de formação quanto de legitimação de, pela e para toda comunidade científica.

A comunidade científica é tanto caracterizada por um saber teórico quanto por uma prática compartilhados. Nesse sentido, entendemos que o elo entre os textos anteriores e o Science Studies e História da Ciência, publicado originalmente em 2009, encontra-se nas relações de aproximação e afastamento entre os participantes dessas, por assim dizer, escolas de pensamento. Grosso modo, a autora reconhece as limitações e os privilégios de ambas, mas aponta para a necessidade de um novo desenvolvimento interdisciplinar acerca "do que a ciência é" e de "como ela funciona".

Enquanto a história da ciência desenvolveu um ethos e práticas cultivadas no escopo da disciplinaridade, os science studies permaneceram "interdisciplinares e indisciplinados". E isso fez com que não se constituíssem enquanto modelo de pensamento ou disciplina bem definidos. Entendemos essa limitação dos science studies como um desvio oportuno e necessário, mesmo para a epistemologia histórica, uma vez que foi possível uma abertura tanto no âmbito social quanto em outros aspectos cognitivos ou não para as pesquisas sobre ciência. Desse modo, essa trajetória marca, ao menos, uma ampla defesa da interseção entre pluralismo e desunidade da ciência hoje ${ }^{2}$, características intrínsecas à análise histórica de conceitos.

Objetividade e Imparcialidade: Virtudes Epistêmicas nas Humanidade, publicado em 2014, é o texto que encerra essa coleção. Daston pretende elidir a frágil correlação entre objetividade e imparcialidade por meio da análise histórica desses conceitos. Trata-se, portanto, de reconhecer a singularidade e a função dos valores em questão para as humanidades. Para isso, ela recorre às críticas de Nietzsche ao homem histórico e à razão objetiva.

1 Ver sobre: FLECK, Ludwik. Gênese e Desenvolvimento de um Fato. Científico. Belo Horizonte: Fabrefactum, 2010.

2 Sobre isso: GALISON, Peter; STUMP, David (org). The Disunity of Science. Stanford: Stanford University Press, 1996. 
Um dos mais curiosos aspectos da história da curiosidade científica é a transmutação da subjetividade desenfreada na mais pura objetividade. Ou, para dizer em outros termos, como o intenso interesse pelos objetos da investigação científica se transformou em desinteresse por tudo o mais. Desinteresse por aquilo que é mais próximo e querido é apenas a forma extrema de um foco preciso de interesse que exclui o restante do universo e concentra todo o intelecto, toda a emoção e energia em um único ponto, como um poderoso e ultrafino raio laser. Essa diferença por 99,9\% do restante do universo, humano e natural, é frequente identificado ao desinteresse ou mesmo à objetividade (DASTON, 2017, p.141-142).

Como uma obsessão ou, ainda, como uma religião, a objetividade é assim apontada como um valor que cria e é criado para e pela produção de conhecimento. "Tratar uma coisa é ipso facto negligenciar outra”, por isso, a historiadora entende que a objetividade nas humanidades seguiu o caminho da especialização em seminários, grupos de pesquisas e conferências, que mais tarde seriam replicados pela Big Science.

Esses sete textos, mais o prefácio escrito também pela autora, compõem o que entendemos como um verdadeiro percurso entre a objetividade e a historicidade. Nesses caminhos encontram-se orientações para uma epistemologia histórica, defendida como um método de análise para os conceitos científicos. E, ainda, um desvio pelo science studies que termina com um desafio aos filósofos, convidando-nos a forjar uma nova forma de interdisciplinaridade. Como gosto de desafios, aceito e convido o leitor e a leitora a conhecerem o dossiê "Gênero e Conhecimento: Saberes localizados e poder" da Revista Em Construção, que será publicado em maio de 2019 !

\section{Referências bibliográficas}

DASTON, Lorraine. Historicidade e objetividade. Tradução: Derley Menezes Alves e Francine Iegelski (Org. Tiago Santos Almeida). São Paulo: Editora LiberArs, 2017.

e GALISON, P. Objectivity. New York: Zone Books, 2010.

FIGUEIRÔA, Silvia F. de M. Objectivity. Revista Eletr. de Com. Inf. e Inov. em Saúde. Rio de Janeiro, v.2, n.2, p.107110, jul.-dez., 2008.

FLECK, Ludwik. Gênese e Desenvolvimento de um Fato Cientifico. Belo Horizonte: Fabrefactum, 2010.

GALISON, Peter; STUMP, David (org). The Disunity of Science. Stanford: Stanford University Press, 1996. 